\title{
GRADING THE HOPE DIAMOND
}

\author{
By Robert Crowningshield
}

\begin{abstract}
For the first time ever, the famous Hope diamond has been graded by a widely recognized system. Although the 45.52-ct weight was confirmed, the GIA Gem Trade Laboratory graders found the clarity-recently reported as "apparently flawless"- to be VS. Color graded "fancy dark grayish blue," the Hope phosphoresces an exciting red to short-wave U.V. radiation.
\end{abstract}

Much has been written about the history of the Hope diamond and especially the misfortunes that have supposedly befallen many who have owned it (see, e.g, Patch, 1976; Balfour, 1987; Krashes, 1988). In the more than 30 years since Harry Winston donated it to the Smithsonian Institution in 1958, however, the Hope has been an object of great admiration. One of the most popular exhibits at the Smithsonian, it is probably seen by more people each year than any other diamond.

Although the Hope has been in the United States for most of the 20th century (since its purchase in 1911 by Evalyn Walsh McLean), it had never been formally graded. In December 1988, the opportunity presented itself when GIA learned that the Hope was being removed from its mounting for a number of reasons, including photography (figure 1) and the making of a model. Several representatives of the New York office of the GIA Gem Trade Laboratory traveled to Washington to prepare a complete grading report on the Hope, the first using a widely recognized grading system.

Earlier individual efforts had already provided some of the required information that would only

\footnotetext{
ABOUT THE AUTHORS

Mr. Crowningshield is vice-president of the GIA Gem Trade Laboratory, Inc., Santa Monica and Now York

Acknowledgments: Dave Hargett, John King, Ingrid Nolte, Eddie Schwartz, Tom Yonelunas, and Phil Yurkiewicz, all of the GIA GEM Trade Laboratory, participated in the grading of the Hope. John Sampson White and Russell Feather, of the Smithsonian Institution, were invaluable in making the arrangements for the grading session.

Gems \& Gemology, Vol. 25, No. 2, pp. 91-94
}

(C) 1989 Gemological Institute of America need to be confirmed for the GTL report. For example, in 1960 GIA's Bert Krashes had tested the stone with a conductometer and determined that it was semiconductive, as is characteristic of natural-color type IIb diamonds, which are usually blue. He also remarked on the red phosphorescence to short-wave ultraviolet radiation. In 1975, Herbert Tillander suggested (in a paper presented at the 15 th International Gemmological Conference) that since the stone had last been weighed before the metric carat had been accepted worldwide, its weight was undoubtedly greater than had heretofore been reported. He subsequently persuaded then-curator Paul Desautels to have the stone unmounted and weighed: It was indeed found to be $45.52 \mathrm{ct}$ rather than the previously published weight of $44.50 \mathrm{ct}$.

The mystery of the Hope is further compounded by Dr. Frederick Pough's recent report (Westman, 1988) that the Hope was recut slightly while in the possession of Harry Winston in the

Figure 1. Since the Hope has been removed from its mounting so seldom in modern times, this is one of the few photographs ever taken of the famous 45.52-ct diamond unmounted. Photo (c) Tino Hammid.

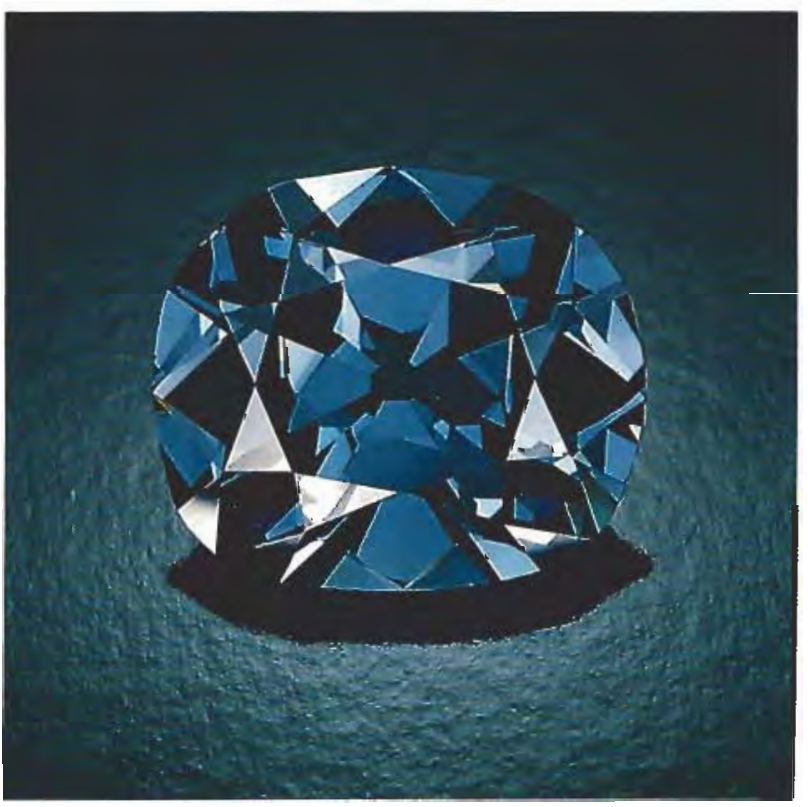




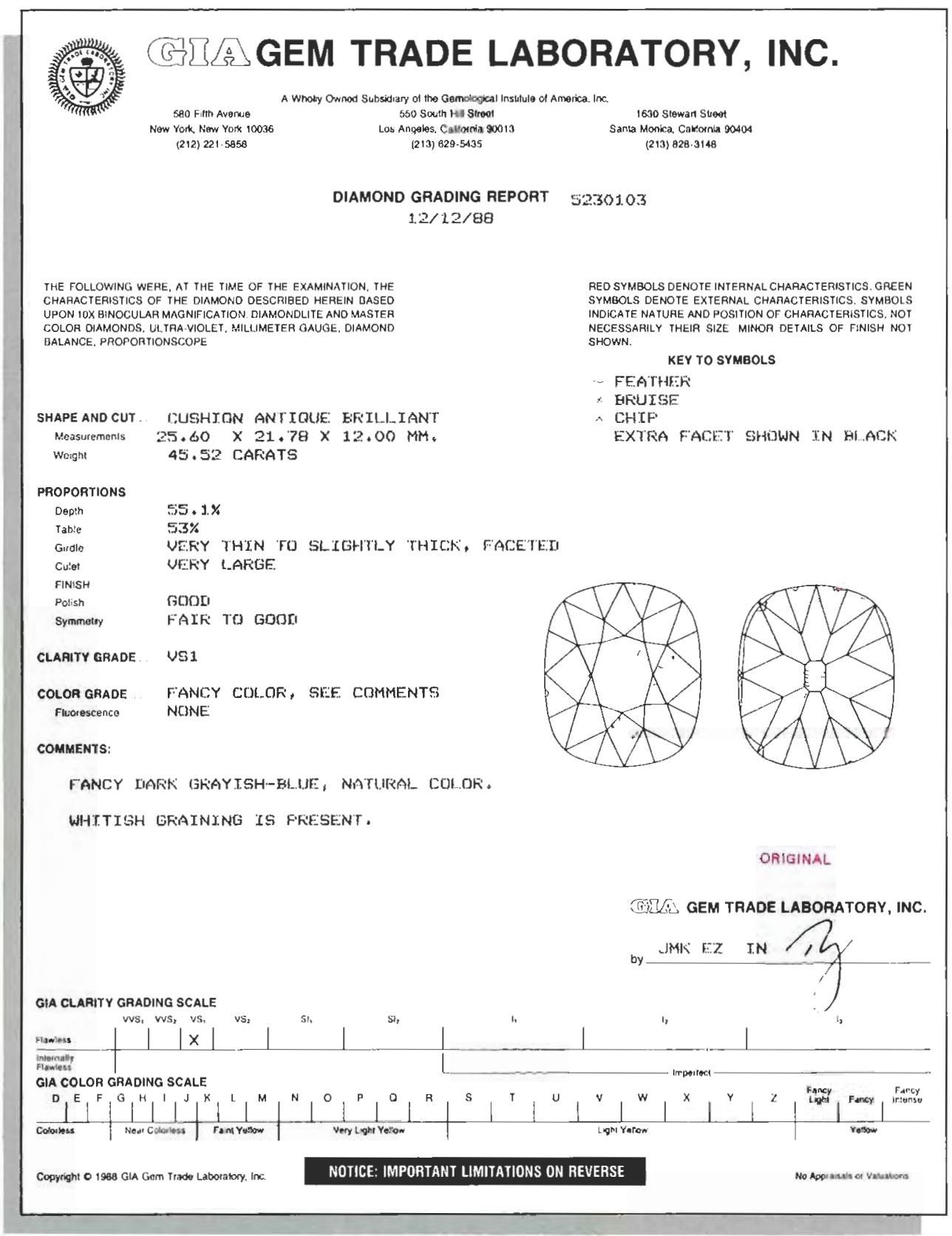

Figure 2. This GIA

Gem Trade Laboratory report represents the first time the Hope has been formally graded by a widely recognized system.

1950s. It is puzzling that the actual weight was not reported to the Smithsonian at the time of donation (J. White, pers. comm., 1989).

For the present study, the GTL staff members provided a Mark V Gemolite microscope, Polaroid plates, a long- and short-wave fluorescence unit, a conductometer, a camera for photography of the inclusions, and two ColorMasters with a fluorescent daylight equivalent source. The results of their efforts are shown in figure 2 and reported below.

\section{SHAPE AND CUT}

In the presence of the graders, Smithsonian gem collection curator John Sampson White weighed the $25.60 \times 21.78 \times 12.00 \mathrm{~mm}$ cushion antique brilliant on an analytical balance. The 45.52 -ct weight reported in 1975 was confirmed.

\section{PROPORTIONS}

We calculated depth percentage to be $55.1 \%$ and the table $53 \%$. The girdle, which is faceted, ranges from very thin to slightly thick. Although the 


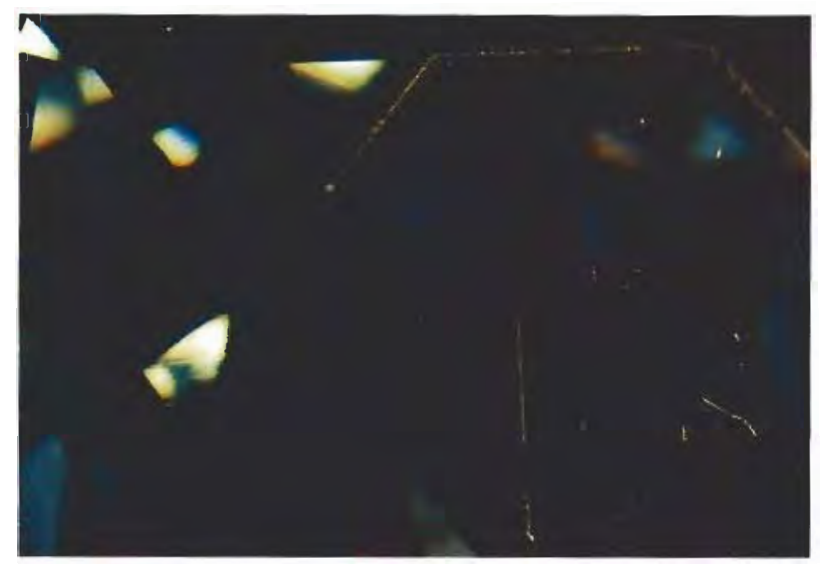

Figure 3. Although historically the Hope was believed to be "of the greatest purity," close examination with $10 \times$ magnification revealed some wear marks, such as the abraded table edge shown here, in addition to a few small feathers and bruises. Photomicrograph by David Hargett.

culet is very large, symmetry was found to be fair to good. The polish is good.

\section{CLARITY GRADE}

The clarity of the Hope has been variously noted as "all perfedtion without specks or flaws" (Françillon, 1812), "of the greatest purity" (Hertz, 1839), "a perfect brilliant" (Bauer, 1904), and "apparently flawless" (1975 Smithsonian data, as reported in Patch, 1976). The GTL clarity grade of VS ${ }_{1}$ was based on the few wear marks that the stone has accumulated during its adventures over the years (figure 3), a few minor feathers, and whitish graining (figure 4). Although whitish graining is characteristic of natural-color blue diamonds, it is not always present to the extent that it will affect the clarity grade, as it does on the Hope. Because of the graining, the highest grade possible for this stone would be a VVS ${ }_{1}$.

\section{COLOR GRADE}

Like the clarity, the color of the Hope has also been described in a number of different ways since the stone in its present form first appeared in the literature in 1812. According to Françillon (1812), the Hope is a "superfine deep blue"; in the Hope catalog (Hertz, 1839), it is described as a "fine deep sapphire blue." The 1975 Smithsonian description (as reported in Patch, 1976) is "dark blue, often described as steel blue."

Our graders determined the color to be a "fancy dark grayish blue." The ColorMaster description

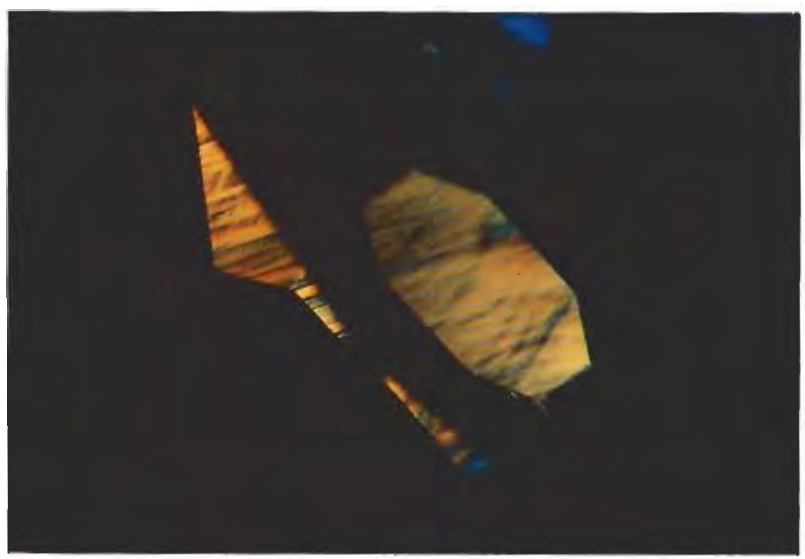

Figure 4. Also affecting the clarity of the Hope is the graining shown here at $10 \times$ magnification. Because of the graining, the clarity could

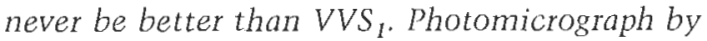
David Hargett.

and notations are: Blue 7.5/1.5 (D 02/25/53). It should be noted here that most blue diamonds have a perceptible amount of gray.

Although there was no fluorescence to longwave ultraviolet radiation, and its presumed red fluorescence to short-wave U.V. appeared to be masked by the visible light from the ultraviolet unit, we were fascinated to see the strong red phosphorescence to short-wave U.V. (figure 5),

Figure 5. One of the most distinctive characteristics of the Hope diamond is its distinct red phosphorescence to short-wave ultraviolet radiation. Photo (C) Tohn Nels Hatleberg.

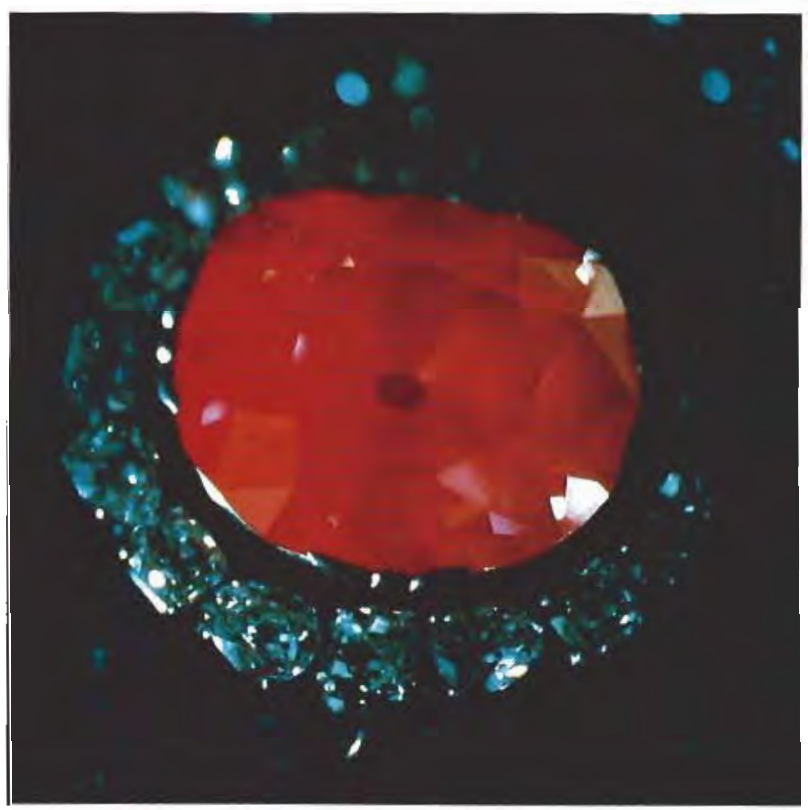


which lasted 15-20 seconds. Such red phosphorescence is not unknown in blue diamonds, but it is limited almost exclusively to dark blue stones and is seldom as intense as that seen in the Hope.

\section{CONCLUSION}

The Hope diamond is undoubtedly one of the most famous stones in the world. Certainly it is the most famous blue diamond - unusual for its large size, depth of color, and the rich, if often tragic, history that has been attributed to it. The grading of the Hope by the GIA Gem Trade Laboratory is part of an ongoing program to more thoroughly document such notable stones (see, e.g, Fryer and Koivula, 1986) for the benefit of future gemologists.

\section{REFERENCES}

Balfour 1. (1987) Famous Diamonds. Collin, London.

Bauer M. (1904) Precious Stones. Reprinted by Charles E. Tuttle Co., Rutland, VT.

Françillon J. (1812) Statement and sketch regarding a 177-grain deep blue diamond. Reproduced in S. S. Patch, Blue Mystery: The Story of the Hope Diamond, Smithsonian Institution Press, Washington, DC, 1976.

Fryer C.W., Koivula J.I. (1986) An examination of four important gems. Gems \&) Gemology, Vol. 22, No. 2, pp. 99-102

Hertz B. (1839) Catalogue of the Collection of Pearls and
Precious Stones Formed by Henry Philip Hope, Esq. William Clowes and Sons, London.

Krashes L. (1988) Harry Winston: The Ultimate leweler, 3rd ed. Harry Winston, lnc., New York, and the Gemological Institute of America, Santa Monica, CA.

Patch S.S. (1976) Blue Mystery: The Story of the Hope Diamond Smithsonian Institution Press, Washington, DC.

Westman B.J. (1988) The enigmatic Hope. Lapidary Fournal, Vol. 41, No. 12 , pp. $42-45,105$.

\section{The GIA Bookstore...}

the most complete gemological bookstore in the world

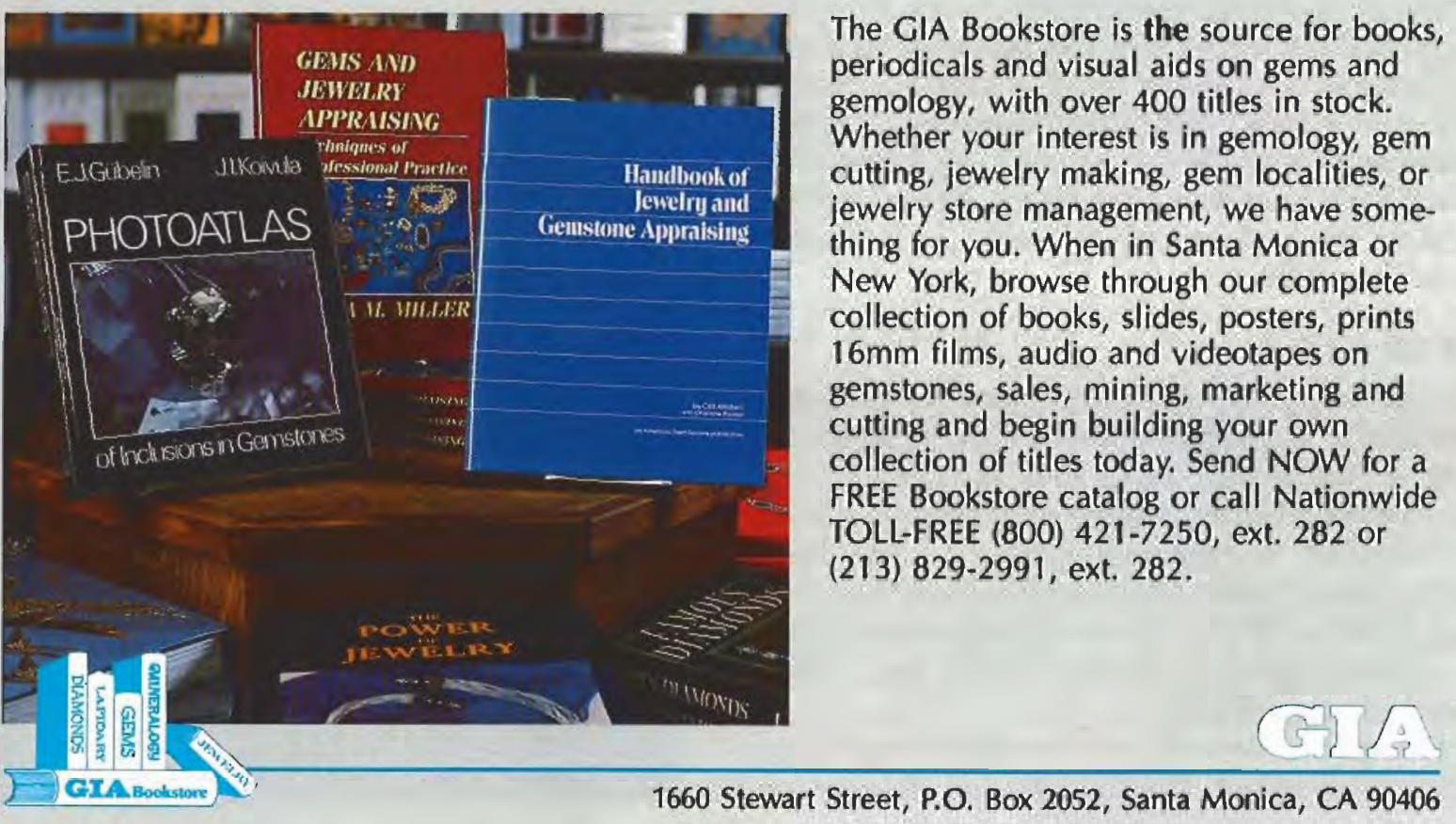

